Vol 11, Issue 12, 2018

\title{
IN VITRO ANTIOXIDANT ACTIVITY AND WOUND HEALING ACTIVITY OF WHEATGRASS BY 1,1- DIPHENYL, 2 PICRYLHYDRAZYL METHOD
}

\author{
VEERMANENI ALEKHYA*, THIYAGARAJAN DEEPAN, MAGHARLA DASARATHA DHANARAJU \\ Department of Pharmacognosy, GIET School of Pharmacy, Rajahmundry, Andhra Pradesh, India. \\ Email: alekhya.veramaneni@gmail.com
}

Received: 05 June 2018, Revised and Accepted: 23 July 2018

\begin{abstract}
Objective: This study was designed to evaluate in vitro antioxidant activity and wound healing activity in Triticum aestivum (wheat grass).

Methods: T. aestivum commonly known as Wheatgrass had a wide range of health benefits among the young grass of common wheat plant components includes chlorophyll, flavonoids, and Vitamins A, C, and E. Wheatgrass is used in Folklore medicine for treatment of skin diseases and wound healing. In our present study, petroleum ether, ethanol and aqueous extracts of T. aestivum have been evaluated for in vitro antioxidant activity and wound healing activity by 1,1- diphenyl, 2 Picrylhydrazyl radical scavenging activity, and Chick chorioallantoic method, respectively.
\end{abstract}

Results: The results of both the assay showed that all the extracts of T. aestivum have significant antioxidant and wound healing activity on dosedependent manner.

Conclusion: The wheatgrass has antioxidant and wound healing activity.

Keywords: Triticum aestivum, Antioxidant, Wound healing activity, Wheatgrass.

(C) 2018 The Authors. Published by Innovare Academic Sciences Pvt Ltd. This is an open access article under the CC BY license (http://creativecommons. org/licenses/by/4. 0/) DOI: http://dx.doi.org/10.22159/ajpcr.2018.v11i12.27705

\section{INTRODUCTION}

Young branch of Triticum aestivum linn (Hindi name - gehun, kanak), Sanskrit name godhuma) is termed as wheatgrass, belonging to the family (Gramineae) [1]. Triticum is the genus of yearly and periodic grasses, yielding numerous types of wheat, inborn to South West Asia and Mediterranean region. It comprises a substantial quantity of iron, phosphorous, magnesium, manganese, copper, and zinc. Wheatgrass is a rich source of tocopherols with high Vitamin E potency. Wheatgrass has a great property to stimulate and enhance body metabolism; restores alkalinity to the blood, due to its alkaline minerals it helps to reduce over acidity in the blood. Wheatgrass helps to restore healthy cells as it is a detoxificant [2]. An extensive scientific research on wheatgrass establishes its anticancer [3,4] and antioxidant potential [5].

In the current study, in vitro antioxidant and wound healing potentials for wheatgrass were assessed. The wound healing potential was estimated by chorioallantoic membrane (CAM) assay. It involves a methodical evolution of measures that establish the integrity of the injured tissue. The wound healing includes different stages including inflammation, granulation, fibrogenesis, neovascularization, wound contraction, and epithelialization [6]. The chick embryo CAM is an extraembryonic membrane. The main function is to exchange nutrients and gasses, which are buttressed by a dense capillary network [7-9]. Due to its widespread vascularization and its ease to use, CAM is extensively utilized as a research tool.

Antioxidants are compounds that protect the cells against the destructive effects of reactive oxygen species such as singlet oxygen, superoxide, Peroxyl radicals, hydroxyl radicals, and Peroxyl nitrite. Cellular damage which is caused by the oxidative stress it is a consequence of inequity between reactive oxygen and antioxidants.

Due to oxidative stress and cellular damage it leads to neurodegenerative diseases (Parkinson's and Alzheimer's) [10] cancer, aging, atherosclerosis, ischemic injury, and inflammation.
Antioxidants are used to inhibit, delay or prevent the oxidation of oxidazole materials by scavenging free radicals and diminishing oxidative stress $[11,12]$. Natural antioxidants have been studied widely for compounds protecting against several diseases interrelated to oxidative stress and free radical-induced damage. Till date, numerous plants have been reported antioxidant properties. In the current study, Tritium aestivum was assessed for the antioxidant property based on the reputation in folklore medical practice [13-15].

\section{METHODS}

\section{Plant collection and identification}

Wheatgrass (T.aestivum) was cultivated and collected from the medicinal garden of Department of Pharmacognosy and Phytochemistry, GIET School of Pharmacy, during the month of June-July 2017 and identified by the botanist from Regional Forest Research Center Rajahmundry, East Godavari District, A.P.

\section{Preparation of the extract}

The collected wheatgrass was washed with water and dried in shade for about 7 days and powdered in a small-scale blender. About 500g of the powdered wheatgrass was subjected for Soxhlet extraction using different solvents such as petroleum ether, chloroform, ethanol, and water. Solvents selection was based on highly polar in nature. Continuous Sox halation was done for around $12 \mathrm{~h}$ for each solvent. The extracts obtained were evaporated at $50-60^{\circ} \mathrm{C}$ using a hot plate. The residues were stored in airtight containers for further research.

\section{Preliminary phytochemical screening}

Preliminary phytochemical screening of the extracts was carried out, and it shows the presence of following components in Table 1.

\section{Antioxidant activity}

1,1- diphenyl, 2 Picrylhydrazyl (DPPH) free radical scavenging assay method was used for the assessment of in vitro antioxidant activity for the plant extracts (petroleum ether, chloroform, ethanol, and water) T. aestivum. 
DPPH radical scavenging activity $[17,19]$

T. aestivum (wheatgrass) antioxidant properties were determined by DPPH free radical scavenging activity. Various extracts of T. aestivum were taken for preparing different concentrations in distilled ethanol. $1 \mathrm{ml}$ of each solution was placed in different test tubes, then added $4 \mathrm{ml}$ of a $0.1 \mathrm{~m}$ ethanol solution, shaked vigorously. The tubes were incubated in a dark room at the RT baseline correction. Changes (decrease in absorbance) at $517 \mathrm{~nm}$ were measured, and percentage quenching of DPPH was calculated using the formula:

Radical scavenging activity $\%=\left[\left(\mathrm{A} 0-\mathrm{A}_{1} / \mathrm{A}_{0}\right) \times 100\right]$

\section{In vitro wound healing activity [18]}

CAM

For in vitro wound healing [16] activity CAM model was used in the present study. In this technique, 9 days old embryonated chicken eggs were selected, and a small $1 \mathrm{~cm}^{2}$ incision was made in the shell. Through this methyl cellulose loaded with different herbal extracts of ethanol concentrations of $25 \mu \mathrm{g}, 50 \mu \mathrm{g}, 100 \mu \mathrm{g}$, and $125 \mu \mathrm{g}$ was placed at the connection of the two large vessels on CAM. Tape was used to seal the incision, and then eggs are incubated for $72 \mathrm{~h}$ in a well-humidified chamber at $37^{\circ} \mathrm{C}$. Then, tape was removed carefully for the observation of a new blood vessel. CAM treated with herbal extracts is compared with CAM containing disc without herbal extract (Control and Standard).

\section{RESULTS}

\section{Antioxidant activity}

Different extracts such as petroleum ether, chloroform, and ethanol and aqueous extracts of T. aestivum have proved that high antioxidant activity when compared to the reference standard. $\mathrm{IC}_{50}$ values of the standard were found to be 25 and for ethanol extract shows high compared to standard. DPPH activity of petroleum ether extracts of T. aestivum is presented in Table 2 and Fig. 5 .

An odd electron is present in DPPH radical is responsible for the absorbance at $517 \mathrm{~nm}$, and it shows visible deep purple color when DPPH accepts an electron donation by an antioxidant compound the DPPH is decolorized, which can be quantitatively measured from the changes in the absorbance. DPPH activity of chloroform extracts of T. aestivum is presented in Table 3 and Fig. 4.

Petroleum ether, chloroform, and ethanol and aqueous extracts of T. aestivum show a significant dose-dependent inhibition of DPPH activity. DPPH activity of ethanol and aqueous extracts of T. aestivum is presented in (Fig. 3 and 6) and (Tables 4 and 5).

\section{Wound healing activity}

The methanolic extract of T. aestivum has a definite pro-healing activity than the normal healing observed by control.Fig. 1 shows methylcellulose disc without herbal extract and Fig. 2 shows methylcellulose disc impregnated with methanolic extract of T. aestivum.

\section{DISCUSSION}

The phytochemical studies reveal the presence of carbohydrates, amino acids, alkaloids, proteins, saponins, and flavonoids. DPPH activity of different extracts of T. aestivum exhibited high antioxidant as compared to that of the standard. Based on the results of the present study, it indicates that T. aestivum having a pro-healing action than that normal healing observed by significant control. Ether, chloroform, and ethanolic extracts of leaf exhibits potential antioxidant activity and wound healing activity in a dose-dependent manner.

\section{CONCLUSION}

Determination of natural antioxidant compounds from plant extracts will help to develop new drug candidates for antioxidant therapy. The plants are the best sources for obtaining natural antioxidant compounds for various medicinal uses. The present study explores the antioxidant
Table 1: Preliminary phytochemical analysis

\begin{tabular}{|c|c|c|}
\hline S. No & Name of the Test & Results \\
\hline 1. & Test for Carbohydrates & \\
\hline a. & Molisch test & + \\
\hline b. & Fehling's test & + \\
\hline c. & Benedicts test & + \\
\hline 2. & Test For proteins & \\
\hline a. & Biuret test & + \\
\hline b. & Xanthoprotein test & + \\
\hline c. & Millions test & + \\
\hline 3. & Test for Amino acids & \\
\hline a. & Ninhydrin test & + \\
\hline 4. & Test for Alkaloids & \\
\hline a. & Dragendroff's test & + \\
\hline b. & Mayer's test & + \\
\hline c. & Hager's test & + \\
\hline d. & Wagner's test & + \\
\hline 5. & Test for Steroids & \\
\hline a. & Salkowski test & - \\
\hline b. & Liebermann reaction & - \\
\hline 6. & Test for Phenols and Tannins & \\
\hline a. & Ferric chloride test & - \\
\hline b. & Lead acetate test & - \\
\hline c. & Dilute Nitric acid test & - \\
\hline 7. & Tests for fixed oils and fats & \\
\hline a. & Saponification test & - \\
\hline b. & Stain test & - \\
\hline 8. & Test for Glycosides & \\
\hline a. & Keller-Kiliani test & - \\
\hline 9. & Test for Saponins & \\
\hline a. & Hemolytic test & + \\
\hline b. & Foam test & + \\
\hline 10. & Test for Flavonoids & + \\
\hline
\end{tabular}

Table 2: DPPH radical scavenging activity of petroleum ether extract of $T$. aestivum

\begin{tabular}{lllllll}
\hline Concentration $(\boldsymbol{\mu l})$ & \multicolumn{2}{l}{ OD 517 nm } & \multicolumn{3}{l}{$\begin{array}{l}\text { \% Antioxidant } \\
\text { activity }\end{array}$} \\
\cline { 2 - 4 } \cline { 6 - 7 } & Sample & Standard $(\boldsymbol{\mu l})$ & & Sample & Standard \\
\hline 50 & 1.212 & 2 & 1.012 & & $*$ & $33.94^{*}$ \\
100 & 1.132 & 4 & 0.980 & & $26.1^{*}$ & $36.03^{*}$ \\
150 & 1.112 & 6 & 0.9 & & $27.41^{*}$ & $41.25^{*}$ \\
200 & 1.002 & 8 & 0.851 & & $34.59^{*}$ & $44.45^{*}$ \\
\hline
\end{tabular}

DPPH: 2.2-Diphenyl-1-picryl hydrazyl, Petroleum ether extract values.

T. aestivum: Triticum aestivum

Table 3: DPPH radical scavenging activity of chloroform extract of $T$. aestivum

\begin{tabular}{lllllll}
\hline Concentration $(\boldsymbol{\mu l})$ & \multicolumn{2}{l}{ OD 517 nm } & \multicolumn{3}{l}{$\begin{array}{l}\text { \% Antioxidant } \\
\text { activity }\end{array}$} \\
\cline { 2 - 4 } \cline { 6 - 7 } & Sample & Standard $(\boldsymbol{\mu l})$ & & Sample & Standard \\
\hline 50 & 1.212 & 2 & 1.012 & & $21.19^{*}$ & $34.2^{*}$ \\
100 & 1.128 & 4 & 0.980 & & $26.65^{*}$ & $36.28^{*}$ \\
150 & 0.110 & 6 & 0.906 & & $27.82^{*}$ & $41.09^{*}$ \\
200 & 0.008 & 8 & 0.851 & & $34.46^{*}$ & $44.66^{*}$ \\
\hline
\end{tabular}

DPPH: 2.2-Diphenyl-1-picryl hydrazyl, Chloroform extract values.

T. aestivum: Triticum aestivum

principles from natural resources. CAM assay is a valuable alternative to the rodent in vivo models for wound healing and even for the study of angiogenesis. CAM in vitro methods are of low cost, short experimental duration easy dynamic observation with minor ethical concerns, and it also has the great accessibility, and easy handling for both intervention and imaging of the vasculature have attracted current researchers. Further 
Table 4: DPPH Radical scavenging activity of Ethanol extract of T. aestivum

\begin{tabular}{|c|c|c|c|c|c|}
\hline \multirow[t]{2}{*}{ Concentration $(\mu \mathrm{l})$} & \multicolumn{3}{|c|}{ OD 517 nm } & \multicolumn{2}{|c|}{$\begin{array}{l}\% \text { Antioxidant } \\
\text { activity }\end{array}$} \\
\hline & Sample & & candard $(\mu \mathrm{l})$ & Sample & Standard \\
\hline 50 & 1.112 & 2 & 1.08 & $23.2^{*}$ & $25.4^{*}$ \\
\hline 100 & 1.028 & 4 & 0.864 & $29^{*}$ & $40.33^{*}$ \\
\hline 150 & 0.812 & 6 & 0.522 & $43.92 *$ & $63.95^{* *}$ \\
\hline 200 & 0.546 & 8 & 0.362 & $62.29^{* *}$ & $75^{* * *}$ \\
\hline
\end{tabular}

DPPH: 2.2-Diphenyl-1-picryl hydrazyl, Ethanol extract values.

T. aestivum: Triticum aestivum

Table 5: DPPH Radical scavenging activity of Aqueous extract of T. aestivum

\begin{tabular}{lllllll}
\hline Concentration $(\boldsymbol{\mu l})$ & \multicolumn{2}{l}{ OD 517 nm } & \multicolumn{3}{l}{$\begin{array}{l}\text { \% Antioxidant } \\
\text { activity }\end{array}$} \\
\cline { 2 - 4 } \cline { 6 - 7 } & Sample & Standard $(\boldsymbol{\mu l})$ & & Sample & Standard \\
\hline 50 & 1.312 & 2 & 1.110 & & $21.49^{*}$ & $23.02^{*}$ \\
100 & 1.042 & 4 & 0.874 & & $27.73^{*}$ & $39.38^{*}$ \\
150 & 0.830 & 6 & 0.532 & & $42.44^{*}$ & $63.1^{* *}$ \\
200 & 0.561 & 8 & 0.382 & & $61.09^{* *}$ & $73.5^{* *}$ \\
\hline
\end{tabular}

DPPH: 2.2-Diphenyl-1-picryl hydrazyl, Aqueous extract values.

T. aestivum: Triticum aestivum

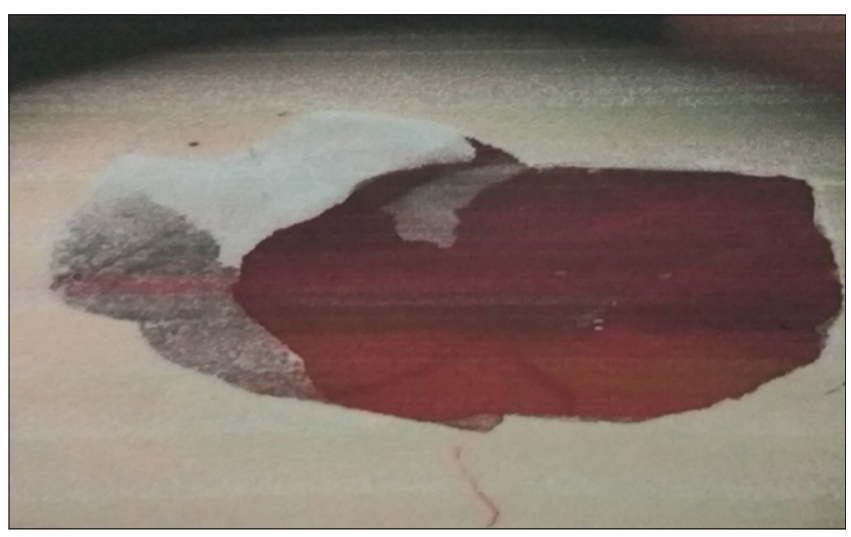

Fig. 1: Chorioallantoic membrane without herbal extract

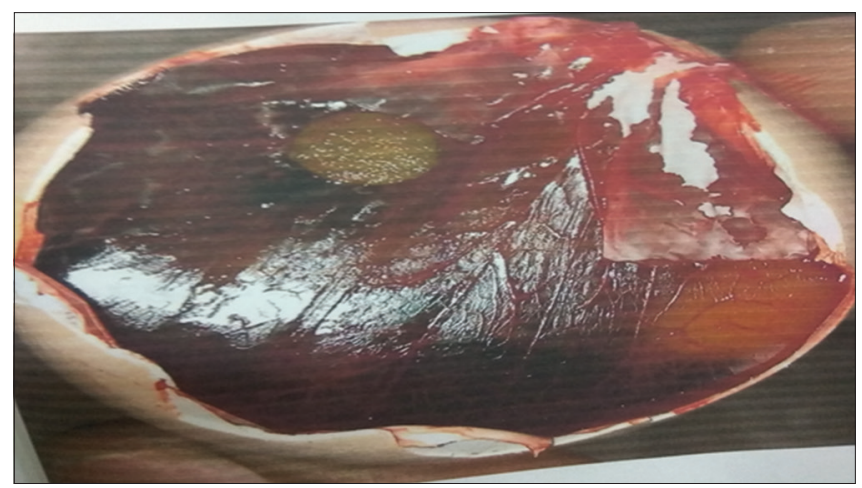

Fig. 2: Chorioallantoic membrane with herbal extract

evaluation of T. aestivum has to be done in treatment and management of wounds.

\section{ACKNOWLEDGMENT}

The author would like to thank management and principal, GIET School of Pharmacy, for providing necessary facilities to carry out the research work.

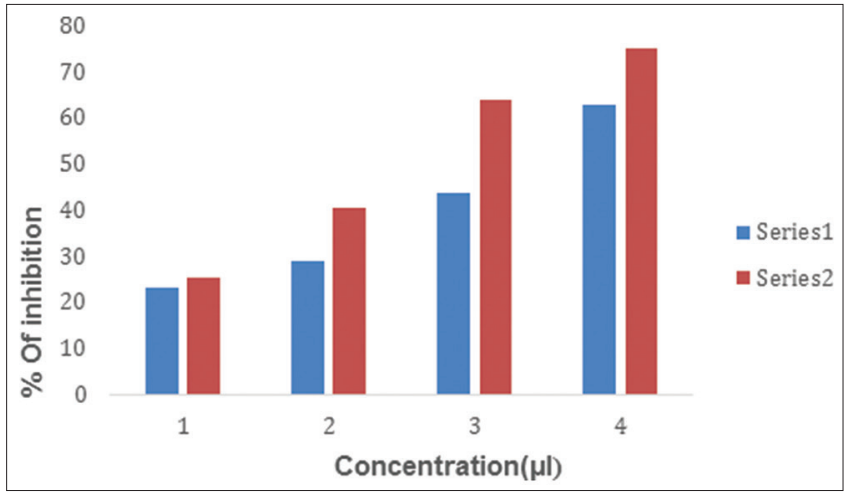

Fig. 3: 1,1- diphenyl, 2 Picrylhydrazyl activity of Triticum aestivum with ethanol extract

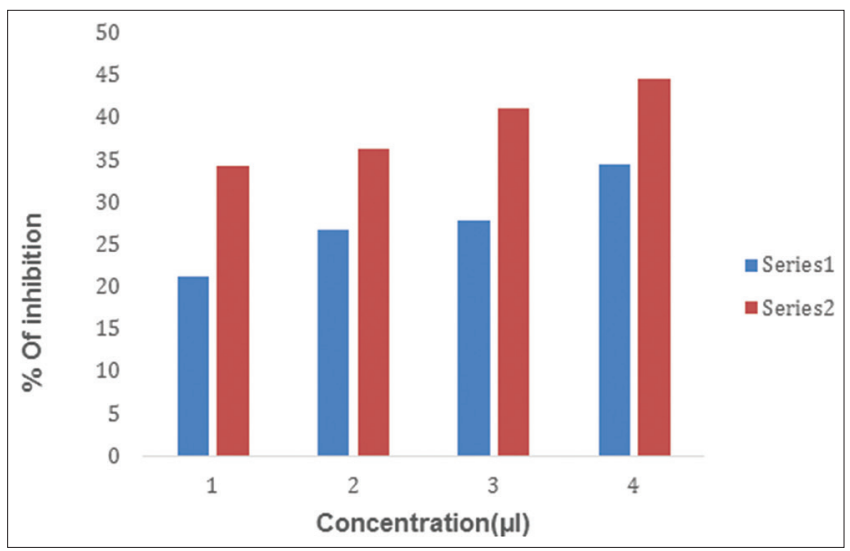

Fig. 4: 1,1- diphenyl, 2 Picrylhydrazyl activity of Triticum aestivum with chloroform extract

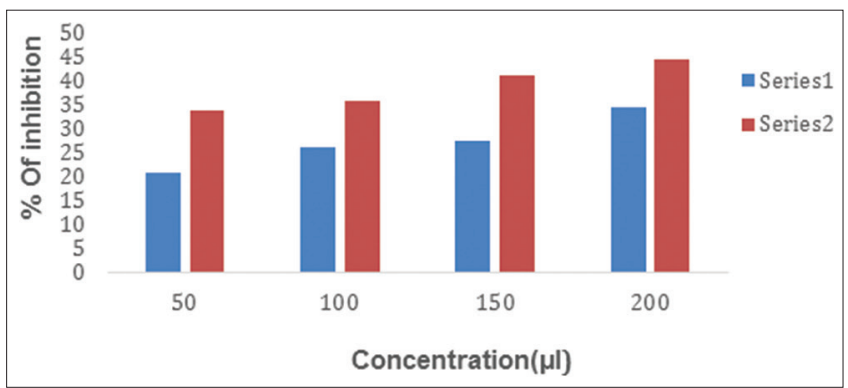

Fig. 5: 1,1- diphenyl, 2 Picrylhydrazyl activity of Triticum aestivum with petroleum ether extract

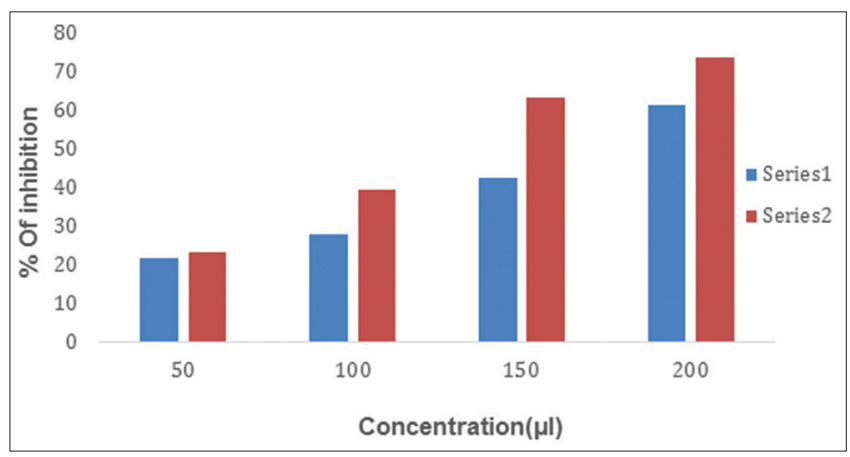

Fig. 6: 1,1- diphenyl, 2 Picrylhydrazyl activity of Triticum aestivum with aqueous extract 


\section{AUTHOR'S CONTRIBUTION}

Mrs. V. Alekhya and Mr. T. Deepan have done the studies and drafted the article. Dr. M. D. Dhana Raju reviewed the article.

\section{CONFLICTS OF INTEREST}

All authors declare that they have no conflicts of interest.

\section{REFERENCES}

1. Wheatgrass. Available from: http://www.en.wikipedia.org/wiki/ wheatgrass.

2. Fahey JW, Stephenson KK, Dinkova-Kostova AT, Egner PA, Kensler TW, Talalay P, et al. Chlorophyll, chlorophyllin and related tetrapyrroles are significant inducers of mammalian phase 2 cytoprotective genes. Carcinogenesis 2005;26:1247-55.

3. Wigmore A. Avery Publishing Group. New York: The Wheat Grass Book; 1986.

4. Ferruzzia MG, Blakesleeb J. Digestion, absorption, and cancer preventative activity of dietary chlorophyll derivatives. Nutr Res $2007 ; 27: 1-12$

5. Kulkarni SD, Tilak JC, Acharya R, Rajurkar NS, Devasagayam TP, Reddy AV, et al. Evaluation of the antioxidant activity of wheatgrass (Triticum aestivum L.) as a function of growth under different conditions. Phytother Res 2006;20:218-27.

6. Clark AF. In: Clark RA, Henson PM, editor. Wound Repair: Overview and General Considerations in the Molecular and Cellular Biology of Wound Repair. New York: Plenum Press; 1996. p. 3-6.

7. Cimpean AM, Ribatti D, Raica M. The chick embryo chorioallantoic membrane as a model to study tumor metastasis. Angiogenesis 2008;11:311-9.
8. Ribatti D. Chicken chorioallantoic membrane angiogenesis model. Methods Mol Biol 2012;843:47-57.

9. Ribatti D. Chick embryo chorioallantoic membrane as a useful tool to study angiogenesis. Int Rev Cell Mol Biol 2008;270:181-224.

10. Saraf S, Ashawat MS, Saraf S. Flavonoids. A nutritional protection against oxidative and UV induced cellular damages. Pharm Rev 2007;1:30-40

11. Duracková Z. Some current insights into oxidative stress. Physiol Res 2010;59:459-69.

12. Reuter S, Gupta SC, Chaturvedi MM, Aggarwal BB. Oxidative stress, inflammation, and cancer: How are they linked? Free Radic Biol Med 2010;49:1603-16.

13. Newman DJ, Cragg GM. Natural products as sources of new drugs over the last 25 years. J Nat Prod 2007;70:461-77.

14. Kaur GJ, Arora DS. Antibacterial and phytochemical screening of Anethum graveolens, Foeniculum vulgare and Trachyspermum ammi. BMC Complement Altern Med 2009;9:30.

15. Blois MS. Antioxidant determinations by the use of a stable free radical Nature 1958;181:119-20

16. Lee G, Luna HT. Manual of Histological Staining Methods of Armed Forces, Institute of Pathology. $3^{\text {rd }}$ ed. New York, Toronto, London, Sydney: American registry of pathology, The Blakiston division; 1968.

17. Kumari A, Ra S. Evaluation of total phenolic, flavonoid content and DPPH free radical scavenging activity of methanolic extract of Ailanthus excelsa roxb. Asian J Pharm Clin Res 2017;10:188-91.

18. Mohanty A, Pal A, Sahu PK. Wound healing activity of Barringtonia acutangula fruit extract. Asian J Pharm Clin Res 2016;9:236-8.

19. Sundari LM, Suja S. Antioxidant and free radical scavenging activity of the mixture of ethanolic extracts of Alpinia speciosa and Alpinia calcarata rhizome. Int J Pharm Pharm Sci 2016;8:164-70. 